\title{
Discussion and Analysis on Student Work of Newly- promoted Undergraduate Universities in China
}

\author{
Song Ping \\ Social Science Planning Office of Henan University of Animal Husbandry and Economy \\ Zhengzhou, Henan, 450046
}

\begin{abstract}
Following with deepening and development of reform of higher education in China, many higher vocational and professional colleges are promoted as undergraduate universities successively. For the purpose of original college student group, that how to adapt new system as soon as possible and to improve student management level stably become important subjects to be solved urgently for such newly promoted undergraduate universities. The paper through literature search and field investigation analyzes the development orientation and student characteristic of newly promoted undergraduate universities and discusses a new approach of student work "Changing Concept, Innovating System, Creating Environment, Establishing Team, Reconstructing Culture and Classified Education".
\end{abstract}

Keywords-Newly promoted undergraduate universities; College; Student management

\section{INTRODUCTION}

Along with rapid propulsion of "popularization" for higher education in China, the important role of applied undergraduate universities in higher education system becomes more and more obvious, many higher vocational and professional colleges are promoted as undergraduate universities successively to adapt social development demand. Newly promoted undergraduate universities aim to establish applied undergraduate universities, which not only conforms to the transformation of higher education from "popular education" to "universal education", but also establishes a platform with clear layer for cultivation of applied talents and broadening of employment channel for undergraduates. Along with changes in structure and quantity of undergraduates and college students, that how to achieve innovation and development of student work under new system has become the important subject to be solved urgently for newly promoted undergraduate universities.

\section{DEVELOPMENT CHARACTERISTICS OF APPLIED UNDERGRADUATE UNIVERSITIES}

The Guiding Opinion on Transformation Development of Local Undergraduate Universities promulgated by the Chinese Ministry of Education proposes that local undergraduate universities shall "take cultivation of high-level technical and skilled talents of first-line production service as main task" and emphasizes "Transformation of newly promoted undergraduate universities to applied undergraduate ones, cultivation of highlevel technology-applied talent and propulsion of industryeducation-research integration". Therefore, applied universities are the regular ones to cultivate high-quality technical talents who can face production, construction, management and serve front line and to serve the local economic construction, regional society and industry development, with main characteristics as below:

In development goal, form characteristics, brand to highlight applicability and specialty; in discipline and specialty, focus on undergraduate education supplemented by higher vocational education, appropriately develop postgraduate education and implement "dual certificate" and "multiplecertificate" system to cultivate applied and innovative talents with multiple skills; in service orientation, take "cultivation of talents mainly for locality" as basic task to become local manpower resource cultivation center and scientific and technological innovation incubation center; in teaching construction, intensify practical teaching, pay attention to practical training base construction both in and out of the university, cultivate students' operational ability and highlight industry-university-research cooperation; in talent cultivation, face locality and serve the basic level and cultivate the comprehensive talents who can skilfully apply knowledge to solve actual production questions, adapt to diversified demands of the industry as well as have strong science and technology application, popularization and transformation abilities; in teachers' construction, take high-quality teachers with gracious ethics, optimized structure, exquisite business skills and vitality as basic guarantee to cultivate "double-certificated" teachers team for the necessary of disciplinary development by multiple ways [1].

Author introduction: Song Ping (1966-), male, born in Nanyang, Henan, an Associate Professor, mainly engaging in research of higher education management.

Project fund: Central plain culture construction and scientific \& technological innovation team construction project, with No. of HUAHE2015012. 


\section{STUdENT CHARACTERISTICS OF NEWLy PROMPTED UNDERGRADUATE UNIVERSITIES}

\section{A. Diversified student levels and different learning purposes}

Most newly promoted undergraduate universities are in the status that "undergraduate and junior college educations" coexist. The universities have undergraduates, junior college students, entrusted-training students jointly cultivated with enterprise and few non-degree education students participating in skill training. Educational systems of students are different due to the different background of the students. Students admitted by regular higher educational institutions are from regular high school or vocational school, most entrustedtraining students are from enterprise and public institutions while non-degree education students are from various aspects of the society. In addition, multi-level of students also decides the complexity of their leaning purposes.

\section{B. Different student sources and various culture bases}

It is found through research that most students of newly promoted undergraduate universities are from rural areas and economic less-developed areas, where the unsubstantial basic education decides uneven student qualities which further decides various goals in future, learning habits, learning motivations and self-study abilities, especially that junior college students and non-degree education students lack correct understanding on learning of cultural courses, are careless on class and homework and have fluke mind for exam etc. These require the universities to manage students differently, but it is impossible to achieve absolute classified education in actual student work, which brings certain difficulty for applied undergraduate universities against cultivation of students.

\section{Prominent self-awareness and weakened collective idea}

Youthful students in the new century have strong selfesteem, subject consciousness and participating awareness. They pay attention to the realization of self-value, actively integrate into society to engage in paid service, advocate ego and pursue individuality. Furthermore, some students persist in their old ways and have thin collective idea and deficient team awareness as well as prevalent self-interest concept and behavior. They do not know what the correct solution is when facing difficulties, have descended anti-pressure and frustration ability and "deal with matters without principle" in living and work.

\section{Prominent psychological problem and prevalent utilitarian idea}

Firstly, it is the extreme confidence of undergraduates. The students who have this mentality place themselves at dominant position and frequently take individual subjective wish as cognitive perspective. They evaluate matters in living with absolute viewpoints such as "I'm sure to succeed", "I'm superior to others" etc, which may make them trap in endless obsession; secondly, general inferiority of junior college students. Although undergraduates and junior college students are in the same university, they have big differences in learning, living, interpersonal communication, etc., which makes junior college students be suspicious of self-capacity and further develops as inferiority; thirdly, mutual belittling between undergraduate and junior college student. The students have different goals in the future due to different levels so that they have communication and interaction problems which results in mutually despise and deny the opposite frequently, this phenomenon not only influences self-development of students, but also brings certain difficulty for education management.

Through survey it is showing that many students measure successful career with money and comfortable, high-end living; some students have the opinion of "work energetically if there is great benefit, work negatively if there is little benefit and do not work if there is no benefit"; however, most students believe that the purpose of learning is to repay parents, change life, improve social status, etc., which reflect the utilitarian of outlook on life and value of students.

\section{E. Vague ideological understanding and thin discipline consciousness}

The survey on ideological situation of students in part newly promoted undergraduate universities reveals that part students have vague ideological understanding. For the question that "socialism may finally defeat capitalism", $37.4 \%$ students reply Disagree and Difficult to Judge; for the question that "socialism and capitalism develop to same direction frequently", 15.9\% students show Difficult to Judge and $43.4 \%$ students agree with the opinion; for the opinion that "privatization is an inexorable trend of China in the future", $38.1 \%$ students agree with the opinion and $19 \%$ students choose Difficult to Judge. Although the students in these universities have strong senses of times and mission, they do not understand their own responsibilities and how to fulfil their responsibilities; For example, for the purpose of "motivation of joining the Party", 61\% students reply development of official career, $63.8 \%$ students reply the need for job hunting while only $34.7 \%$ students reply pursuing ideal and faith [2].

In discipline, firstly, it is the thin study discipline, especially that the students in "order class" have small employment pressure, relax in sprit and lack proactivity in learning, with serious late arrival, early leaving, absence from school, etc.; secondly, a great number of students violate regulations and disciplines. Undisciplined behavior, cheating, drinking, smoking, hitting the internet bars, online load, etc. frequently appear. The insufficient rigid management of the school influences the discipline idea cultivation of students. 


\section{New COUnTERMEASURE OF STUdENT MANAGEMENT FOR NEWLY PROMOTED UNDERGRADUATE UNIVERSITIES}

Student management in newly promoted undergraduate universities shall synchronize with construction of applied undergraduate goal with distinctive characteristics and innovate new work path to fully play its key role in talents cultivation.

\section{A. Master ideological trends and cultivate initiatives}

Related survey shows that mainstream ideological situation of students in current newly promoted undergraduate universities is active, healthy and upward and the students have strong patriotism, political responsibility and awareness of unexpected development; they are full of confidence in socialism with Chinese characteristics; they have strong sense of identity on noble sentiment and moral cultivation, advocate competitive consciousness and aggressiveness spirit; they have mature employment and mate selection psychology as well as pragmatic attitude. Therefore, the university shall concentrate on positive mainstream ideology of students, promote socialist core values, protect and guide positive energy of informal group; mobilize all positive factors to serve for the students' development demand and cultivate positive psychology.

\section{B. Transform educational concept and innovate management measures}

As the development of higher education from popularization to universalness, undergraduate makes diversification requests on service of universities and the particularity of university management becomes more and more significant. Since it is difficult for management of newly promoted undergraduate universities to change original concept of higher vocational and professional colleges within short time departments shall strengthen study and research of undergraduate education management, adapt a series of new challenges brought by promotion of school-running level rapidly and set up new ideas to achieve all-round transformation.

Firstly, set up "student-oriented" work concept. Fully recognize students' personality differences, work out targeted service measures to meet rational diversified demands of students and provide sufficient space for personality development; secondly, encourage students to participate in management. Teachers shall place students at principal position practically, play a good facilitating role, urge system implementation, arouse the enthusiasm of students to participate in school management and support "selfmanagement, self-education and self-service" of students [3]; thirdly, efficiently serve students with high quality. Strengthen "datamation, informatization, refinement, standardization and unification" construction of student service, establish student opinion expression and feedback system, actively explore a management system adaptable to students' characteristics and with moderate strictness, complementary leniency and strictness so that student management can be stepped on scientization and normalization road as soon as possible.

\section{Build guidance mechanism and create growth environment}

Firstly, build motivation guidance mechanism. According to the characteristics and cultivation scheme of different students, implement outstanding and advancement evaluation system based on comprehensive quality assessment by differentiated assessment and evaluation method to guide the students to actively learn and consciously develop an active and healthy attitude towards life [4].

Secondly, build propaganda guidance mechanism; on one hand, propagandize promising future of applied undergraduate education policy and talent development in China with microblog, WeChat group, fetion group, QQ group, etc. to guide the students to set up self-confidence and enhance motive force of development. On the other hand, propagandize various policies of employment and job selection to guide the students to set up correct employment attitude and achieve unification of life value and social value.

Thirdly, build psychological guidance mechanism. According to the psychological characteristics of students such as self-abasement, mutual contempt, mutual disavowal, etc., shift psychological health work forward, early grab general status investigation, build psychological file, pay attention to the students in special group at any time, complete consultation and persuasion and perfect contingency reaction mechanism to timely and efficiently solve mental troubles of students.

\section{Optimize management team and promote service level}

Undergraduates in the new century are not reactive Educates any longer. However, they require respect, understanding, caring as well as hope equal dialogue with the manager. Therefore, student supervisors must actively meet new challenges, watering down and change the plan to fit the new situations.

Firstly, improve strict student work team selection mechanism. Not only attach importance to personal quality, professionalism and dedication spirits, but also pay more attention to concerning students and business quality. Include student evaluation in work assessment standard, constantly perfect evaluation mechanism and accelerate student management team professionalization and expertization; secondly, improve student supervisor training mechanism. Regularly develop business training, theory seminar, visiting communication, field investigation, etc. to constantly promote management and service level; thirdly, improve reward mechanism. Form the work mechanism of "fair assessment", "typical reward" and "example guidance" to arouse the enthusiasm of student management personnel to actively serve for students' development. 


\section{E. Innovate working idea and reconstruct campus culture}

Good campus culture is an effective way to guide and edify students' development and growth. Since most newly promoted undergraduate universities take improvement of postgraduate qualifying examination rate as the main concern to add social reputation, which result in focusing on cultivation of students' specialized theoretical knowledge while pay less attention to the campus culture of students' comprehensive quality. Therefore, newly promoted undergraduate universities shall combine school characteristics, persist in the principles of "combining school and department, giving priority to department, promoting boutique and complementary characteristics" and pay adequate attention to association culture, dormitory culture, cooking culture, social survey, network communication, voluntary service, scientific and technological invention, inspirational loving school, fashion charity, etc. to favourite and acceptable with pleasure by students to [5] actively construct a culture environment beneficial to students' growth and with distinctive characteristics.

\section{F. Apply classified education and management, boost joint development}

Newly promoted undergraduate universities shall centre on education and implement student management by "classified education and personalized guidance" mode according to different characteristics of students.

For undergraduates, adopt the management mode of professional counsellor system to guide students to clear goals, create strong academic atmosphere, help students set up example consciousness and give full play to the advantages of their high qualities, strong learning ability and great influence of professional counsellor so that the students are willing to develop the good habits of endeavour, progressiveness and become a role model; for junior college students, the management mode of counsellor and class teacher assistant may be adopted. The counsellor is mainly to guide class teacher assistant and class teacher assistant shall persist in the principles of "Clearing direction, observing discipline and promoting study style", strengthen education of students on cultivation of civilization quality and cultivate students' self- confidence and good learning behaviour to avoid falling behind for other students, single class teacher management mode may be adopted. The main points are to urge progress, regulation and discipline observation, quality promotion, etc., guide the students to learn from excellent students and promote the students' learning and adaptive capacity so that different students in the same university can learn from each other, learn from other's strong points to offset the deficiencies, develop potential and improve simultaneously.

\section{CONCLUSION}

In conclusion, management of university students is a longterm arduous "comprehensive education" and an "art education" integrating ideology, policy, knowledge and practicalness. Only when changing idea, accurately positioning, focusing on students' ideological and psychological characteristics, innovating method and means, creating growth environment and boosting autonomous management, can newly promoted undergraduate universities achieve "four" effects such as standardized behavior, moral sentiment, healthy culture, etc. of students and powerfully boost realization of applied innovative talent cultivation goal [6].

\section{REFERENCES}

[1] Pan Maoyuan and Che Rushan, Brief Discussion on Positioning of Applied Undergraduate University [J], Higher Education Research, 2009, (5): P36-38

[2] Liu Qingdong, Ideological Situation Investigation Analysis and Countermeasures of Current Undergraduates J, Economy and Society Development, 2009, (3): P199-200.

[3] Cai Zhongxi, Boosting Innovation of University Student Management with Human-oriented Ideology [J], China Economic \& Trade Herald, 2009, (17): P93.

[4] Yang Jinyun, Individuality Education Problems and Countermeasures of Undergraduates in Applied Undergraduate University [J], Economy and Society Development, 2009, (12): P201.

[5] Lv Jing, Discussion on Working Concepts of Student Management for Applied Undergraduate University [J], Social Sciences Journal of Universities in Shanxi, 2012, (1): P79.

[6] He Jiadi, Misunderstanding Analysis and Countermeasures of Autonomous Management Mode for University Students [J], Journal of Yuncheng University, 2009, (8): P102. 